\title{
THE BRITISH JOURNAL OF VENEREAL DISEASES
}

\section{NON-SPECIFIC GENITAL INFECTIONS*}

\section{THE ISOLATION OF ORGANISMS OF THE PLEUROPNEUMONIA GROUP FROM THE GENITAL TRACT AND THEIR RELATION TO THE GONOCOCCUS}

\author{
By M. H. SALAMAN, M.D., Dipl.Bact.
}

Major, R.A.M.C.; Pathologist to the Venereal Diseases Department of a Military Hospital; formerly Research Worker, Cancer Department, St. Bartholomew's Hospital, 'London

When I approached the study of the so-called non-specific genital infections, I hoped that I could treat them as a class, well distinguished from gonorrhoea and other conditions by clinical, if not by pathological features ; I hoped that it might be possible, at least, to say with some confidence that a patient either was or was not suffering from gonorrhoea. These hopes are now dead, and for this and other reasons which will appear later my main interest has shifted from nonspecific infections themselves to the relation between them and gonorrhoea.

There is some conflict of opinion among venereologists on the question whether or not non-specific urethritis-occurring as it does in a number of forms and as a sequel to many diverse conditions-should be regarded as a single clinical entity. I shall not venture to express an opinion on this matter, but when I took up this study it appeared to me that, after one had set aside (1) cases in which there was reason to suspect persistent gonorrhoea, (2) those in which the condition was a sequel to some other specific infection such as dysentery, and (3) those in which there had been chemical or mechanical injury to the mucous membrane, there remained a group of conditions to which no known cause could be assigned. Whether or not this last group is sufficiently well defined to be regarded as a single entity, I do not feel competent to judge.

There is this to be said, however, from the pathological point of view : whatever opinion one may hold as to the unity or diversity of this condition, one is not justified in making the deduction either that it is, or is not, caused by a single infective agent. There are many instances of a single infective agent producing diverse clinical conditions. Syphilis and tuberculosis are examples. Before the discovery of the spirochaete and of the Wassermann reaction, many manifestations of syphilis were thought to be distinct diseases; the wonder is, indeed, how the venereologist in the pre-spirochaetal pre-Wassermann era managed to make as coherent a picture of this protean disease as he did. Examples of the converse are also well known : syphilis and gonorrhoea were not always distinguished before the discovery of their respective causes. Mention is made below of another disease, rat-bite fever, which, although regarded by clinicians as a well defined condition, can be caused by either of two entirely different organisms.

Thus, whatever our opinion may be as to the clinical homogeneity of nonspecific urethritis, it is, I think, wise to approach the problem of its causation with an entirely open mind.

I do not discuss here the many theories which have been put forward to account for this condition or group of conditions. Harkness, at one of the 1945 meetings of the Medical Society for the Study of Venereal Diseases, described certain observations which suggest that some cases of urethritis may be due to a virus. Others have suggested that some cases of male urethritis are due to Trichomonas vaginalis and have succeeded in demonstrating this organism in discharges.

\footnotetext{
* An address to the Medical Society for the Study of Venereal Diseases, 26th Jan., 1946.
} 
It is a practical necessity in work of this kind to limit oneself to the testing of one hypothesis at a time. For reasons which are stated below, it seemed to be likely that organisms of the pleuropneumonia group might be the cause of some genital infections. With the assistance of my colleagues in the venereal division of the Royal Victoria Hospital, I undertook the investigations described, with the object of testing this hypothesis.

\section{Organisms of the pleuropneumonia group}

The pleuropneumonia-like organisms are not very well known, although they are much more widely distributed than is generally supposed. A good general survey of what was known of them, and of the literature of the subject, up to 1941, is given by Sabin. They possess well defined and remarkable characters, by which they can be recognized readily. Extremely exacting in their growth requirements, they grow slowly on media enriched with a native protein ; on solid media they form small colonies with a central boss and a flattened periphery. Smears taken from these colonies do not show any formed elements, only a mass of amorphous debris. Impression preparations, made by a suitable technique by which the whole colony is transferred bodily to the slide, display the characteristic features. Although different members of the group vary in their colonial form, they have certain features in common when examined in this way. The colony consists of a framework of very fine filaments, more or less radially arranged, in the meshes of which are clusters of vesicles varying in size from 2 to 10 microns (diameter) or more. These vesicles are by far the most conspicuous part of the growth and sometimes quite obscure the filamentous elements. They have a lipoid envelope, and contain tiny granules which stain well with Giemsa's stain (see Fig. 4). When a suspension of the organism is passed through a filter which is known to hold back ordinary bacteria, and the filtrate is inoculated on to a suitable medium, the typical colonies develop. It is reasonable to suppose that it is the granules visible within the vesicles in stained preparations which are the filterable elements.

Thus, these organisms may be said to occupy a place intermediate between bacteria and viruses. Like viruses they are filterable through bacteria-proof filters, but unlike them they are able to grow on non-living media. They resemble viruses in another way: their granule-containing vesicles are very much like the large intracellular inclusions formed by the viruses of psittacosis, lymphogranuloma inguinale and trachoma, which also consist of a delicate envelope packed with granules -.$"$ elementary bodies".

Most of the species of this group are animal pathogens; others have been found in tissues or secretions of apparently healthy animals. A species typical of the group is the cause of an important disease of cattle, namely pleuropneumonia. This organism has been recovered from the lungs and most of the other organs of cattle ; it is present in the blood during part of the illness. Many other species have been isolated from various animals. Rodents are particularly susceptible ; in these animals, one of the typical lesions is a purulent arthritis. Strains have also been isolated from apparently normal rats and mice.

\section{Streptobacillus moniliformis and the $\mathbf{L}$ organism}

In 1925 Levaditi, Nicolau and Poincloux isolated an organism from the blood of one of themselves, who suffered from intermittent fever with an erythematous rash and multiple arthralgia. They described it as consisting of bacilli arranged in chains, together with various bizarre forms, including long filaments and clear vacuoles; this organism they called Streptobacillus moniliformis. Ten years later Klieneberger. succeeded in separating from this organism a typical member of the pleuropneumonia group, which in her hands bred true and did not reproduce the bacillary forms. She regards Streptobacillus moniliformis as a mixture of two organisms : a pleuropneumonia-like component which she called " $\mathrm{L}_{1}$,", and a streptobacillus. Other workers have succeeded in separating out the $\mathrm{L}_{1}$ component, but in their hands it has always reverted, reproducing bacillary forms. In 1942 Brown and Nunemaker showed that the human disease known as rat-bite 
fever, commonly ascribed to infection with Spirillum minus, is probably heterogeneous, some cases being caused by the spirillum and some by Streptobacillus moniliformis; they isolated the latter from the blood of several cases in which the spirillum could not be found. They agree with Klieneberger that Streptobacillus moniliformis produces structures similar to the pleuropneumonia organism, but they believe that both these and its bacillary forms are stages in the life cycle of a single organism. The controversy on the nature of this organism has a bearing on the work which is discussed below.

\section{Organisms of the pleuropneumonia group in the human genital tract}

There have been a number of reports in recent years of the isolation of organisms of the pleuropneumonia group from the genital tracts of men and women. Dienes and his associates in America have published reports on the isolation of $\mathrm{L}$ organisms-I use this convenient term of Klieneberger's-from the cervical, vaginal, and urethral secretions of women, also from the urethral and prostatic secretions of men (Dienes ; Dienes and Smith). Some of the women were suffering from gonorrhoea, some from non-specific inflammations, some from arthritis, but some were clinically normal ; all the men, however, showed signs of chronic prostatitis. Beveridge, in Australia, has confirmed the occurrence of $L$ organisms in the male urethra. He found them in 4 out of 24 non-specific urethral discharges*.

Klieneberger-Nobel, working at the Whitechapel Clinic and the London Hospital, isolated $L$ organisms from vaginal secretions of 18 out of 45 women attending the venereal diseases department, 12 out of 36 attending the gynaecological department and suffering from various presumably non-venereal conditions, but only. 7 out of 50 women attending the antenatal clinic. Of those 7 women 5 were suffering, or had suffered, from some complication of pregnancy.

These figures, considered as evidence for the causative role of $L$ organisms in non-specific genital infections, are hardly impressive. It must be remembered, however, that these organisms are difficult to grow and that they are still more difficult to isolate.

\section{Methods of investigation}

In our series, a large number of men and women suffering from various genital infections, together with some presumably normal controls, were examined for the presence of $\mathrm{L}$ organisms.

After a number of special media had been tried, it was found that $L$ organisms of genital origin could be detected growing on ordinary 10 per cent chocolate agar, as used for growing the gonococcus. Neither special additions nor any adjustment of the hydrogen ion concentration were found to be necessary. This was a great saving of time and materials. The routine cultures from the urethral discharge, urinary deposit and prostatovesicular secretion, in the case of men, and from the cervix and urethra in that of women, were incubated for 48 hours in an atmosphere containing an increased carbon dioxide content, and then treated with 1 per cent dimethyl-p-phenylenediamine hydrochloride, for detection of gonococcal colonies, in the usual way. When the plates were quite dry, pieces of medium bearing possible $\mathrm{L}$ colonies were cut out and placed face downwards on slides. These were flooded with Bouin's fixative fluid, then put into a moist chamber in the ineubator overnight. Next day, when the agar was peeled off, the colonies remained adherent to the slides. These were put into 75 per cent alcohol for $\frac{1}{2}-1$ hour, rinsed in distilled water, and stained in 4 per cent Giemsa's stain for 4 hours, then lightly differentiated and dehydrated in graded acetone-xylol mixtures, cleared in xylol, and mounted in a neutral mountant, such as D.P.X. mounting medium. L colonies in these preparations can be distinguished with the $\frac{2}{3}$ inch objective. This method of fixing and staining, which is one used by Klieneberger and Smiles, but with modifications by Dr. C. Robinow, has proved to be simple and reliable; it can be recommended especially to those who have had no previous experience of this group of organisms. (Further details of the method will be found in an article by Salaman and his collaborators.) 


\section{Results of the investigation}

These are given in Tables 1 and 2.

Male urethritis and prostatitis (see Table 1).-L organisms were cultured from the urethral discharge, or occasionally from the urine only, in 12 out of 35 of cases of gonorrhoea. They were found much more rarely in primary non-specific urethritis ( 3 out of 45 cases) and in the similar condition which often follows gonorrhoea ( 2 out of 34 cases). These results offer no real evidence to suggest that non-specific urethritis is due to $L$ infection. There is no evidence that $L$ organisms are responsible for prostatitis : no correlation was found between the presence of $L$ infection and clinical signs of prostatitis. A larger survey is needed, however, to establish this point with certainty. In a group of 28 men from a skin department, with no obvious signs of urethritis, L organisms were found in the urethra, urine, or both, in 4 cases ; 4 of the group showed slight pyuria, but only one of these cases was $\mathrm{L}$ positive. Thus it is possible, as previous work has indicated, that L organisms may exist in the urethra or elsewhere in the genitourinary tract without causing symptoms. Here, also, a larger survey is needed.

TABLE 1-URETHRITIS AND PROSTATITIS IN MALES

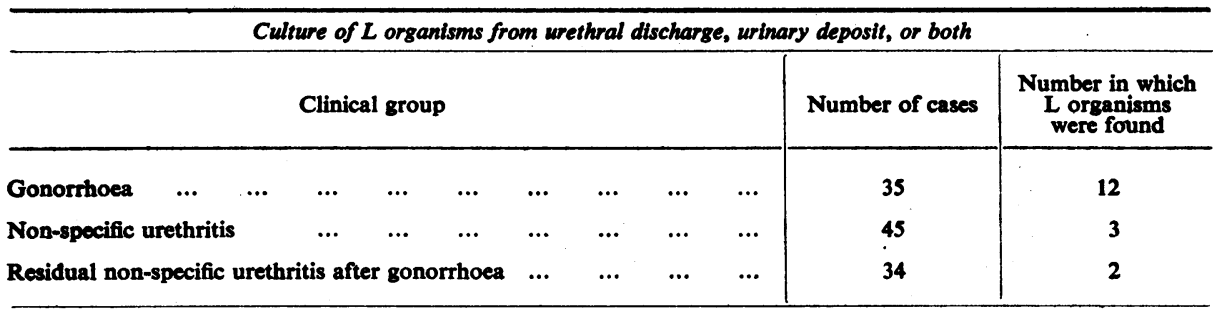

Culture of $L$ organisms from prostato-vesicular flutas

\begin{tabular}{|c|c|c|c|c|c|c|c|c|}
\hline \multicolumn{7}{|c|}{ Clinical group } & \multirow{2}{*}{ Number of cases } & \multirow{2}{*}{$\frac{\begin{array}{c}\text { Number in which } \\
\text { L organisms } \\
\text { were found }\end{array}}{2}$} \\
\hline Cases without signs of prostatitis & $\cdots$ & $\cdots$ & $\cdots$ & $\cdots$ & $\dddot{\dddot{q}}$ & $\cdots$ & & \\
\hline Cases with signs of prostatitis ... & $\cdots$ & ... & $\cdots$ & $\cdots$ & $\cdots$ & $\cdots$ & 9 & 1 \\
\hline
\end{tabular}

" Normal " controls (men from a skin disease department) : culture of L organisms from urethra, urinary deposit, or both

\begin{tabular}{|c|c|c|c|c|c|c|c|c|c|}
\hline \multicolumn{8}{|c|}{ Clinical group } & \multirow{2}{*}{$\frac{\text { Number of cases }}{24}$} & \multirow{2}{*}{$\frac{\begin{array}{c}\text { Number in which } \\
\mathbf{L} \text { organisms } \\
\text { were found }\end{array}}{3}$} \\
\hline Cases without signs of ge & -urin & dis & & $\cdots$ & $\cdots$ & $\cdots$ & $\cdots$ & & \\
\hline Cases with slight pyuria & $\cdots$ & $\cdots$ & $\cdots$ & $\cdots$ & $\cdots$ & $\cdots$ & $\cdots$ & 4 & 1 \\
\hline
\end{tabular}

Genital infections in the female (see Table 2).-L organisms were found in cultures from the cervix, the urethra, or both, in 11 out of 18 cases of gonorrhoea, in 39 out of 63 cases of trichomonal vaginitis, and in all of 20 cases in which the two conditions co-existed. They were found in 8 out of 18 cases of non-specific cervicitis, and in 6 out of 8 cases in which this condition was complicated by trichomonal vaginitis. In this connexion it should be remembered that gonorrhoea in women is often masked, particularly when Trichomonas vaginalis is present. It is possible, therefore, that in women there is an even closer association than is apparent between the gonococcus and the L organisms. In addition, 17 clinically normal women were examined; L organisms were cultured from only one of them. It must be noted, however, that many women, after apparently successful treatment for gonorrhoea or trichomonal vaginitis, were clinically normal also ; yet several of these cases yielded $L$ organisms.

Local treatment of trichomonal vaginitis with pentavalent organic arsenic 
greatly reduces the frequency of culture of $L$ organisms, at any rate for a time. The treatment of gonorrhoea or of non-specific cervicitis in women by means of penicillin or of sulphathiazole may have some effect, but the figures are not significant. L organisms were obtained in profuse, almost pure, culture from the cervix and urethra of a woman with trichomonal vaginitis, two days after the completion of a course of penicillin injections given for syphilis $(2,400,000$ units in the course of $7 \frac{1}{2}$ days) (Salaman and his collaborators).

TABLE 2-GENITAL INFECTIONS IN FEMALES





\section{Organisms of the pleuropneumonia group in gonorrhoea}

So far the work had yielded no very decisive results. The role of $L$ organisms in genital infections was certainly not proved. Nevertheless, the frequent association of the gonococcus with $L$ organisms was notable. In our series, they were found in about one-third of the number of men and not quite two-thirds of the number of women with gonorrhoea.

Association of the L organism with the gonococcus.-It will be necessary to describe in rather greater detail some of the features of this association. $\mathrm{L}$ organisms appearing in cultures of gonorrhoeal discharges are of two distinct types. In one type the $\mathrm{L}$ organisms form separate colonies, just as they do in cultures from non-gonorrhoeal material, and $\mathrm{L}$ colonies and gonococcal colonies may be seen growing side by side. In the other type separate $\mathrm{L}$ colonies are not found, but in the substance of the gonococcal colonies distinct vesicles, similar to those of independently growing $L$ organisms, can be seen interspersed with the cocci. These L-like forms are seen most distinctly in the periphery of gonococcal colonies in impression preparations, but they are probably scattered all through the substance of the colony. (See Fig. 2, and compare with Fig. 1.)

Sensitivity of the L organism to penicillin. - L organisms were tested for sensitivity to penicillin, by the use of the method of inhibition zones. The method is as follows : a suitable concentration of penicillin is applied to a culture plate at one point, either as a watery solution in a small porcelain cylinder, or, more conveniently, as a blob of penicillin cream, such as is used for skin infections. (I am indebted to Professor Bedson for the latter method.) After incubation the penicillin is surrounded by a zone of inhibition of growth, the diameter of which is a rough measure of the sensitivity of the organism which is being tested. I have found that 
those $\mathrm{L}$ organisms which form separate colonies are relatively insensitive to penicillin. When I tested strains of gonococci which showed the admixture of L-like growth which I have described, a remarkable phenomenon appeared. Remote from the penicillin the gonococcal colonies were seen to contain scattered vesicles; nearer to the penicillin these became larger and more abundant, until, on the edge of the zone of complete inhibition of growth, small colonies were seen which were indistinguishable from pure $\mathrm{L}$ colonies. The cocci had disappeared and only the vesicles, containing minute granules, remained. (See Fig. 4.)

Demonstration of L-like forms in gonococcal strains.-It happened that I was asked to test a certain gonococcal strain for sensitivity to penicillin. It came from a patient in whom gonorrhoea had resisted penicillin treatment. It was a strain in which, when it was cultured in the absence of penicillin, no L-like forms could be seen. It turned out to be normally sensitive to penicillin, but $\mathrm{I}$ was surprised to find that it suffered exactly the same transformation in the presence of penicillin as I had observed in strains which had shown vesicles in the absence of penicillin. I realized that it might be possible by the use of penicillin to demonstrate L-like forms in other strains of gonococci hitherto thought to be pure ; hence, assuming that this transformation indicated the presence of an $\mathrm{L}$ organism, it was also possible that my previous estimate of the frequency of the association between gonococci and L organisms might be well below the true figure. Accordingly I began to collect and culture strains of gonococci from different patients and to test the effect of penicillin on them in the way described above. So far over 80 strains have been examined and L-like forms have been seen in all. Some have been found to retain them through as many as 50 passages in culture.

The detection of $\mathrm{L}$ organisms in gonococcal strains is not new. Dienes, and later Brown and Hayes, demonstrated L-like growth in cultures of several apparently pure strains. Something further, however, emerges from the observations described here. L organisms are not merely occasional contaminants of gonococcal cultures ; by the use of penicillin it is possible to demonstrate L-like structures in every freshly isolated strain.

\section{Interpretation of the results}

Gonococci are well known to be very pleomorphic and often give rise to bizarre and swollen forms, especially in old cultures. May it not be that the structures which I have observed are involution forms of the gonococcus, appearing in the presence of penicillin in greater number than in ordinary cultures ? Involution or degeneration forms are characteristically variable; these L-like forms are remarkably constant in shape and arrangement. There is no suggestion of partial lysis, and there are no ghost cells : all that one finds on the edge of the zone of penicillin inhibition are well developed colonies of a characteristic $L$ form. The close similarity to $\mathrm{L}$ organisms is apparent both in gross and fine structures. The vesicles in these gonococcal cultures are indistinguishable from those of $\mathrm{L}$ organisms, not only in their form and arrangement but also in the minute granules which they contain. It is hard to believe that such a detailed correspondence can be due to chance. (Compare Figs. 3 and 4.)

It has not yet been possible to subculture the apparently pure L-like colonies which grow at the edge of the penicillin zone on a gonococcal plate. Subcultures taken from this position grew either a few gonococcal colonies or nothing at all. This may be merely because I have not discovered the right way or the right moment to subculture them. Perhaps prolonged action of penicillin, although it allows early growth, finally kills them. More work must be done before these questions can be answered with certainty. Although the possibility that the L-like forms in gonococcal cultures may be degenerative stages of the gonococcus cannot be rigidly excluded, I believe it to be very unlikely.

At this stage I do not think that it is possible to distinguish with certainty between this interpretation and three other alternatives: (1) that $L$ organisms invariably contaminate gonococcal strains of genital origin; (2) that gonococci 
PLATE 1.



Fig. 1. The edge of a gonococcal colony, showing no L-like structures. Incubation 48 hours. Magnification $=\times 1000$.

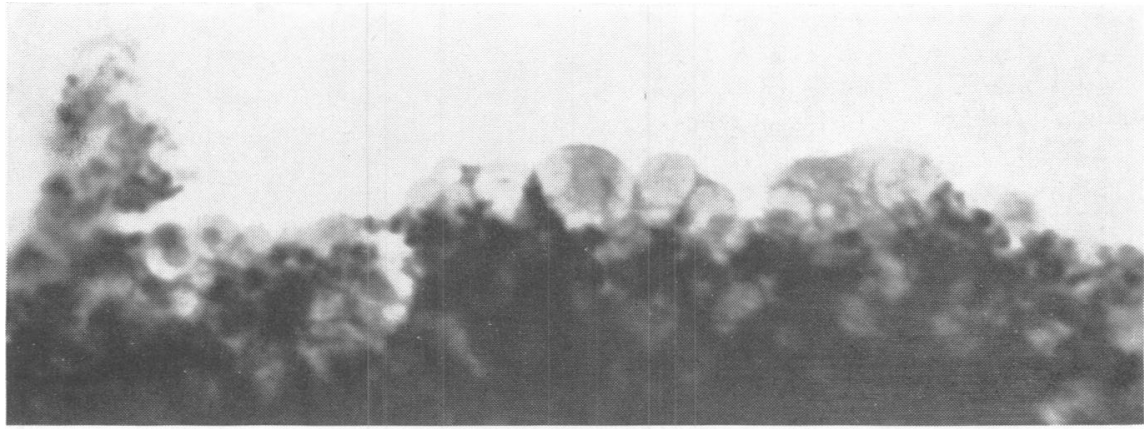

Fig. 2. The edge of a gonococcal colony showing L-like vesicles projecting from the mass of cocci. Incubation 48 hours. Magnification $=\times 1350$. 
PLATE 2.

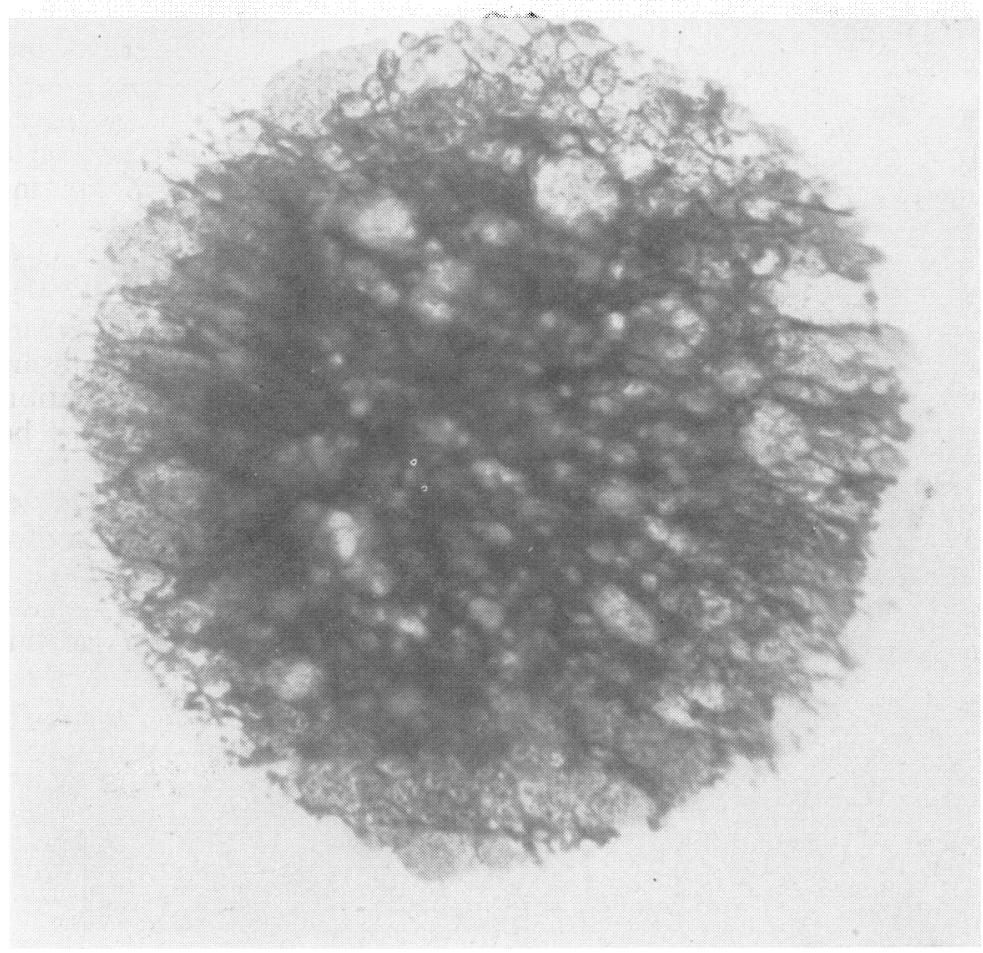

Fig. 3. A colony of an $L$ organism isolated from the urethra of a case of trichomonal vaginitis. Incubation 3 days. Magnification $=\times 700$.

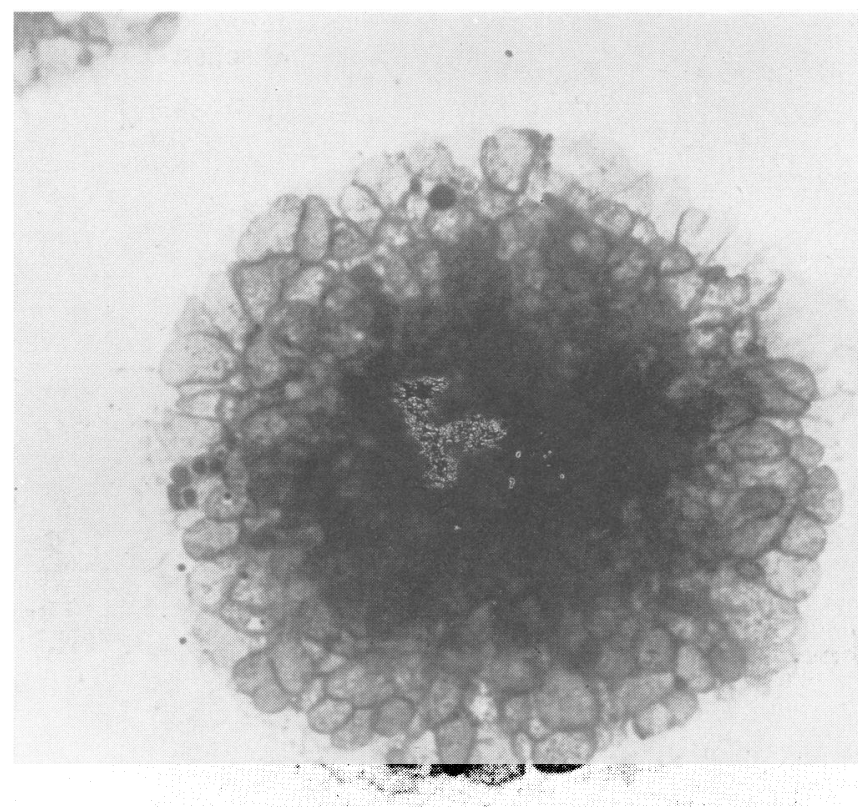

Fig. 4. A gonococcal colony at the edge of the zone of penicillin inhibition. Incubation 48 hours. Magnification $=\times 690 . \quad$ (Note similc ity to Fig. 3.) 
and L organisms live in obligate symbiosis ; (3) that the L-like structures observed are stages in a complex life cycle of the gonococcus.

The last possibility is not as fantastic as it sounds. I have already described the conflict of opinion concerning the relation between Streptobacillus moniliformis and " $\mathrm{L}_{1}$ ", the component separated from it by Klieneberger. Many workers zonsider these to be stages in the life cycle of a single organism, although their discoverer still maintains that they are two distinct organisms. There are infications, too, that other bacterial species may pass through L-like stages.

It would be premature to attempt to deduce the possible bearing on clinical nereology of the facts reported. It is shown above that the occurrence of $L$

anisms in various types of genital infections gives no indication of their ssative role. The demonstration of a 100 per cent association of $L$ organisms ith the gonococcus would put the matter in quite a new light. As this association :s not yet proved, anything that is said about its possible significance must be egarded as tentative.

If the gonococcus can exist in another form - a form which is difficult to grow, and impossible to detect in ordinary smears - we have a possible explanation of a great deal that has hitherto been obscure. Alternatively, if it turns out that we are dealing with two distinct, although habitually associated, organisms, the case from the clinical point of view is not very different. When we remember that this other form - or other organism, whichever it is-has a strong resemblance to a group of organisms which has a preference for the joints, the hypothesis that it may play an important part in genital infections begins to look attractive.

I should like to emphasize, in conculsion, that this is only a progress report of work which is far from complete. At present it is not possible to do more than indicate the direction in which the observations seem to point.

\section{Summary}

Organisms of the pleuropneumonia group (L organisms) were isolated from inflammatory exudates of the genital tract of men and women. They were commonly found in association with the gonococcus. A proportion of gonococcal strains show L-like structures in their colonies. When grown in the presence of penicillin, all the gonococcal strains examined (over 80 in number) showed an L-like type of growth. The significance of these observations is discussed.

*In a second report, recently published, Beveridge, Campbell and Lind describe the culture of $L$ organisms from urethral washings from 14 out of 70 men with non-specific urethritis. Similar cultures from 67 normal medical students were all negative. L organisms were grown from cervical swabs taken from 3 out of 11 women from whom men were said to have contracted non-specific urethritis, but swabs from 17 out of 101 women attending a gynæcological clinic were also positive. The sera of patients with non-specific urethritis were tested for complementfixing antibodies against antigens made from 2 strains of $L$ organisms isolated from cases of non-specific urethritis. The proportion of positiye reactions was significantly greater than among sera from nomal blood donors, but not significantly greater than among sera sent for the Wassermann reaction.

I am indebted to Colonel W. P. Croker, A.M.S., Officer Commanding, Royal Victoria Hospital, Netley, for permission to report these findings ; to Mr. A. J. King, formerly Officer in Charge of the Venereal Division, and to my other colleagues, past and present, who have given me invaluable help with the clinical side of this work; to Mrs. KlienebergerNobel for valuable advice and the gift of two of her classical $L$ strains for comparison; to Dr. C. Robinow for advice and help in the early stages of the work and for taking the photographs ; to the Editor of the Journal of Pathology and Bacteriology for permission to reproduce the matter contained in Tables 1 and 2 ; finally, to my technical staff, without whose assistance the investigation would not have been possible.

\section{REFERENCES}

Beveridge, W. I. B. (1943) Med. J. Aust., 2, 479.

- Campbell, A. D., and Lind, Patricia E. (1946), Med. J. Aust., 1, 179.

Brown, T. McP., and Hayes, G. S. (1942) J. Bact., 43, 82.

- and Nunemaker, J. C. (1942) Johns Hopk. Hosp. Bull., 70, 201.

Dienes, L. (1940) Proc. Soc. exp. Biol., N.Y., 44, 468, 470.

- and Smith, W. E. (1942) Proc. Soc. exp. Biol., N.Y., 50, 99.

Harkness, A. H. (1945) Brit. J. vener. Dis., 21, 93. 
Klieneberger, Emmy (1935) J. Path. Bact., 40, 93. - and Smiles, J. (1942) J. Hyg., Camb., 42, 110.

Klieneberger-Nobel, E. (1945) Lancet, 2, 46.

Levaditi, C., Nicolau, S. and Poincloux, P. (1925) C.R. Acad. Sci., Paris, 180, 1188.

Sabin, A. B. (1941) Bact. Revs., 5, 1.

Salaman, M. H., King, A. J., Bell, H. J., Wilkinson, A. E., Gallagher, Eva, Kirk; C., Howarth, Irene E., and Keppich, P. H. (1946) J. Path. Bact., 58, 31.

\section{DISCUSSION ON THE PRECEDING PAPER}

Air-Cdre. G. L. M. McElligott (the President) said that Maj. Salaman's paper threw new light on the problem of non-specific urethritis. He would be interested to know whether or not the organisms described by Maj. Salaman were insensitive to sulphonamides in vitro.

Maj. Salaman said, with regard to independently grown organisms, that they were as insensitive to sulphonamides as to penicillin. With regard to those which he saw in the gonococcal colonies, he could give no answer.

Mr. A. J. King said that he had had the good fortune to be present when Maj. Salaman first began this experimental work, and that he had been interested in the early results. He was even more interested in what he had heard that afternoon, much of which was new to him. From the very first-even with a technique which was then untried-Maj. Salaman had been able to grow the L organisms from many female subjects, but he had been less successful with specimens from the male. This might be due to some minor error of technique, which prevailed more against his results in the male than in the female. It was an interesting point that the trichomonas parasite which seemed to be associated commonly with the $\mathrm{L}$ organisms was also easy to find in the female and difficult in the male. Maj. Salaman had previously found these $L$ organisms in mixed culture with gonococci, but now it seemed that they were present in what appeared to be pure cultures of all the strains of gonococci which he had tested.

Although nothing was yet proved with regard to the pathogenicity of these organisms, this work did open up fascinating possibilities. The results were particularly interesting to clinicians, especially those who had long held the view that it was very difficult to draw a hard-and-fast line between gonococcal infections and so-called non-specific genital infections. Such a hardand-fast barrier did not fit in with the common clinical findings in the non-specific cases." If Maj. Salaman's theory received further support in the future, it would help to explain some of the puzzling facts which the clinician customarily encountered.

Dr. I. N. O. Price had been interested in this subject whilst working at the Whitechapel Clinic but, unfortunately, owing to staff difficulties, he could not follow it up as he would have liked to have done. He could not help being fascinated by the idea that the gonococcus was not what they had thought it was and that it had a life cycle. If this theory were correct, it would explain many things which happened in the routine bacteriological work of a venereal diseases clinic. For instance, the workers in his laboratory had noticed that when gonococcal antigen was being prepared for the gonococcal fixation test, every now and again a batch would be produced which was inactive, and the only thing to do then was to throw it away. The reason for this unsatisfactory result was never apparent. Every process was carried out in the same way as usual and yet the finished product was of no use.

Another point made by Dr. Price was that in the routine examination of vesicular cultures he and his colleagues had found that it was always more satisfactory to incubate the plates for at least 4-5 days. If this were done, a larger number of positive results were obtained. If the plates were incubated for a shorter time, there was a corresponding diminution in the number of cultures in which gonococci were seen. Whether or not that was due to the L form of organism reverting back to the gonococcus during the incubation, he did not know.

Furthermore, whilst working on subcultures of the gonococcus, incubated for 48 or 72 hours, every now and then he found that, even when he had taken a particularly good culture of the gonococcus and subcultured it, it did not grow. There appeared to be no reason for this, as the conditions of incubation were the same in all the cases. The subculture failed to grow for no apparent reason. When this happened one saw a pale, transparent streak, which looked as if it had no structure whatsoever. On transferring this specimen to a slide and staining it, there was nothing to be seen.

With these experiences in mind, Dr. Price could not help wondering whether there was not more in the idea, that the gonococcus had a life cycle of which the L organism was a part, than had previously been supposed.

Col. L. W. Harrison, after saying that he had seldom listened to a more fascinating paper, asked a question about the possibility of making an antigen of the independently growing $L$ organism.

Maj. Salaman replied that he thought that this would be practicable, but at the moment he could not even subculture the $L$ component of the gonococcus. 